Ger J Exerc Sport Res 2021 · 51:430-442 https://doi.org/10.1007/s12662-021-00764-0 Received: 23 March 2021

Accepted: 20 September 2021

Published online: 15 October 2021

(c) The Author(s) 2021

Thomas Jürgen Klotzbier $(\mathbb{D}$ · Heide Korbus • Bettina Johnen · Nadja Schott

Department of Sport and Exercise Science, University of Stuttgart, Stuttgart, Germany

\title{
Evaluation of the instrumented Timed Up and Go test as a tool to measure exercise intervention effects in nursing home residents: results from a PROCARE substudy
}

ties. Thus, a reduced level of independent mobility is a predictor of institutionalization (Von Bonsdorff, Rantanen, Laukkanen, Suutama, \& Heikkinen, 2006), fall incidents (Sterke, Huisman, van Beeck, Looman, \& van der Cammen, 2010; McGough, Logsdon, Kelly, \& Teri, 2013), dependence, and mortality and is also inversely associated with quality of life (Davis et al., 2015). Furthermore, mobility in daily life depends on an intact sensorimotor system and this is also associated with intact cognition and psychosocial factors in older adults (Bunn, Dickinson, Barnett-Page, Mcinnes, \& Horton, 2008; Costello, Kafchinski, Vrazel, \& Sullivan, 2011).

Independent mobility is routinely assessed with field tests such as the Timed Up and Go (TUG) test (Podsiadlo \& Richardson, 1991). This test can be used diagnostically to guide appropriate interventions, especially considering the subphases within the TUG. Traditionally, only the total duration of the TUG test is assessed using a stopwatch. In contrast, using an instrumented TUG (iTUG) with sensors (e.g., Cimolin et al., 2019; Zarzeczny et al., 2017) provides the opportunity to examine the subphases more closely, including getting up from a chair, walking, turning around, and sitting down again. This helps to identify individual weaknesses and provides the opportunity of targeted training to improve functional mobility (Schoene et al., 2013). While some studies used the iTUG in different populations and clinical conditions (e.g., Zampieri et al., 2010 in Parkinson's disease; Mirelman et al., 2014 in mild cognitive impairment), to our knowledge, there is only one study with nursing home residents (Zarzeczny et al., 2017). This study investigated the subphases of the iTUG in nursing home residents based on quantitative wearable sensors. The authors demonstrated that vertical sit-to-stand acceleration correlated best with subject age $\left(r^{2}=0.430, p<0.05\right)$, suggesting that age-related decreases in TUG performance are primarily associated with decreases in "explosive" lower extremity muscle strength. However, Zarzeczny et al. (2017) only considered cross-sectional findings; studies on intervention effects are not available.

Similarly, the TUG has been widely used to evaluate the effects of different intervention programs related to physical functioning and balance (Baum, Jarjoura, Polen, Faur, \& Rutecki, 2003; Toulotte, Fabre, Dangremont, Lensel, \& Thévenon, 2003; Netz, Axelrad, \& Argov, 2007; Wollesen et al., 2020). There is strong evidence that supports the claim that strength-, balance- and gaittraining can improve mobility in older adults (de Labra, Guimaraes-Pinheiro, Maseda, Lorenzo, \& Millán-Calenti, 
Table 1 Sample characteristics of nursing home residents categorized into percentiles depending on the attendance rates, including mean values (standard deviation) and statistical analyses of the mean value differences

\begin{tabular}{|c|c|c|c|c|}
\hline & $\begin{array}{l}\text { Low attendance } \\
\text { rate } \\
<1 / 3\end{array}$ & $\begin{array}{l}\text { Moderate atten- } \\
\text { dance rate } \\
1 / 3-2 / 3\end{array}$ & $\begin{array}{l}\text { High attendance } \\
\text { rate } \\
\geq 2 / 3\end{array}$ & $\begin{array}{l}\text { Statistical analy- } \\
\text { ses }\end{array}$ \\
\hline & $n=10$ & $n=8$ & $n=32$ & \\
\hline $\begin{array}{l}\text { Attendance } \\
\text { (\%) }\end{array}$ & $\begin{array}{l}3.09( \pm 5.26) ; \\
\text { [range: } 0-15.6 \text { ] }\end{array}$ & $\begin{array}{l}50.1( \pm 10.1) ; \\
\text { [range: } 37.5-63.0 \text { ] }\end{array}$ & $\begin{array}{l}88.3( \pm 10.3) ; \\
\text { [range: } 68.8-100 \text { ] }\end{array}$ & $\begin{array}{l}F(2,47)=0.318^{* * *} \\
\eta_{p}^{2}=0.931\end{array}$ \\
\hline Age (years) & $82.8 \pm 8.93$ & $81.9 \pm 6.1$ & $80.8 \pm 6.6$ & $\begin{array}{l}F(2,47)=0.326^{\text {ns }} \\
\eta^{2} p=0.011\end{array}$ \\
\hline Sex ( $n$ female) & 7 & 6 & 21 & $\mathrm{X}^{2}(2)=0.281^{\mathrm{ns}}$ \\
\hline Weight (kg) & $69.4 \pm 17.4$ & $63.1 \pm 20.9$ & $71.0 \pm 14.8$ & $\begin{array}{l}F(2,47)=0.756^{\text {ns }} \\
\eta^{2} p=0.031\end{array}$ \\
\hline Height $(\mathrm{cm})$ & $1.62 \pm 0.06$ & $1.62 \pm 0.08$ & $1.63 \pm 0.10^{\mathrm{a}}$ & $\begin{array}{l}F(2,46)=0.106^{\text {ns }} \\
\eta_{p}^{2}=0.005\end{array}$ \\
\hline BMI $\left(\mathrm{kg} / \mathrm{m}^{2}\right)$ & $26.2 \pm 5.77$ & $23.8 \pm 6.16$ & $26.9 \pm 5.11^{\mathrm{a}}$ & $\begin{array}{l}F(2,46)=1.04^{\mathrm{ns}} \\
\eta_{p}^{2}=0.043\end{array}$ \\
\hline $\begin{array}{l}\text { Underweight } \\
\text { (n) }\end{array}$ & 0 & 2 & 0 & $X^{2}(2)=10.9^{*}$ \\
\hline $\begin{array}{l}\text { Normal weight } \\
(n)\end{array}$ & 5 & 4 & 14 & $X^{2}(2)=0.107^{n s}$ \\
\hline Overweight (n) & 2 & 0 & 8 & $X^{2}(2)=2.61^{n s}$ \\
\hline Obese $(n)$ & 2 & 2 & 7 & $X^{2}(2)=0.007^{n s}$ \\
\hline $\begin{array}{l}\text { Severely obese } \\
(n)\end{array}$ & 1 & 0 & 2 & $X^{2}(2)=0.789^{n s}$ \\
\hline $\begin{array}{l}\text { Walking aid }(n \text {; } \\
\%)\end{array}$ & $5(50 \%)$ & $8(100 \%)$ & 25 (78.1\%) & $X^{2}(2)=7.55^{n s}$ \\
\hline $\begin{array}{l}\text { MoCA (score); } \\
\text { ( } n<19 \text { pts) }\end{array}$ & $\begin{array}{l}14.5 \pm 6.69 \\
n=8\end{array}$ & $\begin{array}{l}17.7 \pm 4.58 \\
n=4\end{array}$ & $\begin{array}{l}17.1 \pm 6.15 \\
n=19\end{array}$ & $\begin{array}{l}F(2,46)=0.843^{n s} \\
\eta_{p}^{2}=0.035\end{array}$ \\
\hline $\begin{array}{l}\text { Barthel Index } \\
\text { (pts) }\end{array}$ & $73.5 \pm 19.6$ & $82.9 \pm 15.2$ & $75.0 \pm 18.9$ & $\begin{array}{l}F(2,46)=0.697^{\text {ns }} \\
\eta^{2}=0.030\end{array}$ \\
\hline \multicolumn{5}{|c|}{$\begin{array}{l}\text { ns not significant, pts points, BMI body mass index, MoCA Montreal Cognitive Assessment Falls re- } \\
\text { ported } 6 \text { months before and } 6 \text { months after the intervention were considered } \\
\text { Participants were grouped as underweight (BMI < 18.5) non overweight (BMI, 18.5-24.9), overweight } \\
\text { (BMI, 25.0-29.9), obese (BMI, 30.0-34.9), and severely obese (BMI } \geq 35) \text { (Villareal, Apovian, Kushner, \& } \\
\text { Klein, 2005; NHLBI Expert Panel, 1998) } \\
\text { aIn one resident with high attendance rate, height was not recorded and therefore BMI could not be } \\
\text { calculated } \\
{ }^{*} p<0.05,{ }^{* * *} p<0.001\end{array}$} \\
\hline
\end{tabular}

2015). In their meta-analysis, Hortobágyi et al. (2015) found that coordination training, resistance training, and multimodal training significantly improved gait speed in healthy older adults, obtaining the highest effect size for multimodal training interventions (effect size $=0.86$ ). Multimodal interventions have also shown to effectively maintain (Trautwein et al., 2020) or even improve gait abilities (Kocic et al., 2018; Kovacs, Sztruhar Jonasne, Karoczi, Korpos, \& Gondos, 2013; Sakamoto \& Miura, 2016) in nursing home residents. Arrieta, Rezola-Pardo, Gil, Irazusta, \& RodriguezLarrad (2018) published a systematic review to identify randomized controlled tutionalized older adults, the purpose of the study was to (1) examine the iTUG as an instrument to measure the effects of a multicomponent exercise intervention on physical function and balance in nursing home residents and to identify subphases of the iTUG that are more responsive to intervention effects than others. We hypothesized that older adults in long-term care show positive effects in all subphases of the iTUG, and in particular, show improvements in the walking phase because the intervention focused heavily on that aspect. We also wanted to (2) evaluate the impact of the attendance rate on iTUG improvement, since little is known about the dose-response ratio concerning actual attendance. In some cases, the attendance rate is reported in intervention studies, but a defined adherence rate above which participation can be described as successful are hardly to be found. For a more differentiated consideration of the intervention effects, it is therefore necessary to take into account the attendance rate. In a comparable setting, Fairhall et al. (2012) were able to show that in a multifactorial interdisciplinary intervention higher adherence was significantly associated with better performance for most mobility outcomes. Thus, we expect the intervention effects to be significant only at higher attendance rates.

\section{Methods}

\section{Ethics}

physical exercise intervention studies that assessed gait ability in older longterm nursing home residents using concurrent walking speed and TUG tests. This overview shows that some studies that evaluated multicomponent exercise interventions reported improvements in the TUG test after the intervention (Cadore et al., 2014; Lazowski et al., 1999), whereas other studies showed similar (Au-Yeung et al., 2002) or worse results (Dechamps et al., 2010; SerraRexach et al., 2011). However, no subphases were considered in all these studies.

To determine the generalizability of these findings to larger cohorts of insti-
This study took place as part of the PROCARE project-Prevention and occupational health in long-term care study (Cordes et al., 2019). The ethics committee of the Hamburg Chamber of Physicians, Germany, approved the study protocol of the PROCARE project (PV5762).

\section{Participants}

A total of 50 long-term nursing home residents (34 women, $82.7 \pm 6.46$ [range: 65-91] years; 16 men, $78.6 \pm 7.0$ [range: 62-90] years, cf. participant characteristics in - Table 1) were recruited in six different nursing homes located in the 
city of Stuttgart, Germany. All nursing home residents or their legal guardians gave written informed consent before enrolling in the study. Inclusion criteria included: (i) willingness to participate, (ii) the ability to understand and carry out simple instructions, (iii) the ability to walk $10 \mathrm{~m}$ with or without a walking aid, and (iv) the ability to participate in group activities (Bischoff, Cordes, Meixner, Schoene, Voelcker-Rehage, \& Wollesen, 2021). The nursing staff and principal investigators assessed the eligibility criteria. The experimental procedure was explained in detail to the participants. In the general training literature, adherence is defined as successful when participants complete at least twothirds of the training program (HawleyHague, Horne, Skelton, \& Todd, 2016; King et al., 1997). Other papers specify a minimum level of participation for low adherence rate, $<30 \%$ of exercise classes (Tiedemann, Sherrington, \& Lord, 2011). For this reason, participants were divided into three groups based on their attendance rates in the multicomponent exercise intervention: group 1 with attendance rates up to $33.2 \%$ (low), group 2 with attendance rates between 33.3 and $66.6 \%$ (moderate), and group 3 with attendance rates higher than $66.6 \%$ (high; - Table 1).

\section{Instruments}

\section{Instrumented Timed Up and Go test.}

The Timed Up and Go (TUG) test is one of the most common tests used to examine balance, gait speed, and functional ability related to the performance of basic activities of daily living (ADL) in older populations (Herman et al., 2011; Podsiadlo \& Richardson, 1991). It can also help track clinical changes over time (Podsiadlo \& Richardson, 1991). The TUG measures the time it takes a participant to stand up from a chair, walk $3 \mathrm{~m}$ at a comfortable speed, walk around a cone, walk back, and sit down on the chair. If individuals require less than $10 \mathrm{~s}$, they are considered to have free mobility. The time frame between $10-20$ s is considered to have independent mobility. If the task is completed in $20-29$ s, the individual has variable mobility, and if

Ger J Exerc Sport Res 2021 · 51:430-442 https://doi.org/10.1007/s12662-021-00764-0

(c) The Author(s) 2021

T. J. Klotzbier · H. Korbus · B. Johnen · N. Schott

\section{Evaluation of the instrumented Timed Up and Go test as a tool to measure exercise intervention effects in nursing home residents: results from a PROCARE substudy}

Abstract

Background and objectives. To achieve independence in activities of daily living, a certain level of functional ability is necessary. The instrumented Timed Up and Go (iTUG) test provides guidance for appropriate interventions, for example, when considering the subphases within the TUG. Therefore, we evaluated the iTUG as a tool to measure the effects of a multicomponent exercise intervention on the iTUG subphases in nursing home residents.

Methods. Fifty long-term nursing home residents (34 women, $82.7 \pm 6.46$ [65-91] years; 16 men, $78.6 \pm 7.0$ [62-90] years) performed the iTUG test before and after a 16-week intervention period ( $2 \times 45-60 \mathrm{~min} /$ week). According to the attendance rates, participants were divided into three groups.

Results. The total iTUG duration decreased from baseline to posttest, $F(2,46)=3.50$, $p=0.038, \eta_{p}^{2}=0.132$. We observed significant correlations between the attendance rates and the total iTUG duration $(r(50)=0.328$, $p=0.010$ ). However, we did not observe significant group $\times$ time interaction effects in the subphases. The Barthel Index moderated the effect between attendance rate and the total duration of the iTUG test, $\Delta \mathrm{R}^{2}=8.34 \%$, $F(1,44)=4.69, p=0.036,95 \% \mathrm{Cl}[0.001,0.027]$. Conclusions. We confirmed the effectiveness of the iTUG as a tool to measure exercise intervention effects in nursing home residents, especially when participants exhibit high attendance rates. That said, mobility needs to be considered in a more differentiated way, taking into account parameters in the subphases to detect changes more sensitively and to derive recommendations in a more individualized way.

\section{Keywords}

Nursing home residents - Adherence . Functional ability - Balance - Multicomponent exercise intervention · Gait it takes the individual more than $29 \mathrm{~s}$, the individual has impaired mobility (Podsiadlo \& Richardson, 1991). With a "cut-off" value of $14 \mathrm{~s}$ or more, the TUG is considered a good predictor for identifying healthy individuals at risk of falling (Shumway-Cook, Brauer, \& Woollacott, 2000; Allison, Painter, Emory, Whitehurst, \& Raby, 2013). Internal consistency, reliability, validity, and responsiveness are excellent, as reported by Galhardas, Raimundo, and Marmeleira (2020), with an intraclass correlation coefficient (ICC) of 0.99 in older nursing home residents.

Recently, new emerging technologies allow for the recording of gait and postural transitions with wearable devices. In the present study, Opal ${ }^{\mathrm{Tm}}$ sensor modules and Mobility Lab ${ }^{\mathrm{Tm}}$ system (APDM Mobility Lab, APDM Inc., Portland, OR, USA) were used to measure the iTUG test and its subphases. A total of six inertial sensors $\left(\mathrm{Opal}^{\mathrm{TM}}\right)$ were attached to the trunk, lower back, left and right foot, and left and right wrist (• Fig. 1). The sensors were placed with a velcro belt and straps. The Mobility Lab ${ }^{\mathrm{Tx}}$ software analyzed the raw data from all sensors using an integrated and automatic algorithm to calculate the durations of the iTUG subphases. Upon completion of the analysis, Mobility Lab ${ }^{\text {mix }}$ displayed the data in all subphases in a full report that includes all tested trials and parameters.

The iTUG test can be divided into four major subphases: sit-to-stand, walk, turn, and stand-to-sit. The duration of each of these subphases was automatically calculated (see Supplementary Figure). Sit-to-Stand is the time required to stand up at the beginning of the task. Walk is the time required to walk at a normal walking pace to the cone at a distance of $3 \mathrm{~m}$, plus the time required to return back to the chair. Turn is the time required to perform the $180^{\circ}$ turn. Stand-to-sit is the time required to sit down at the end of the task (- Fig. 2). The total duration 


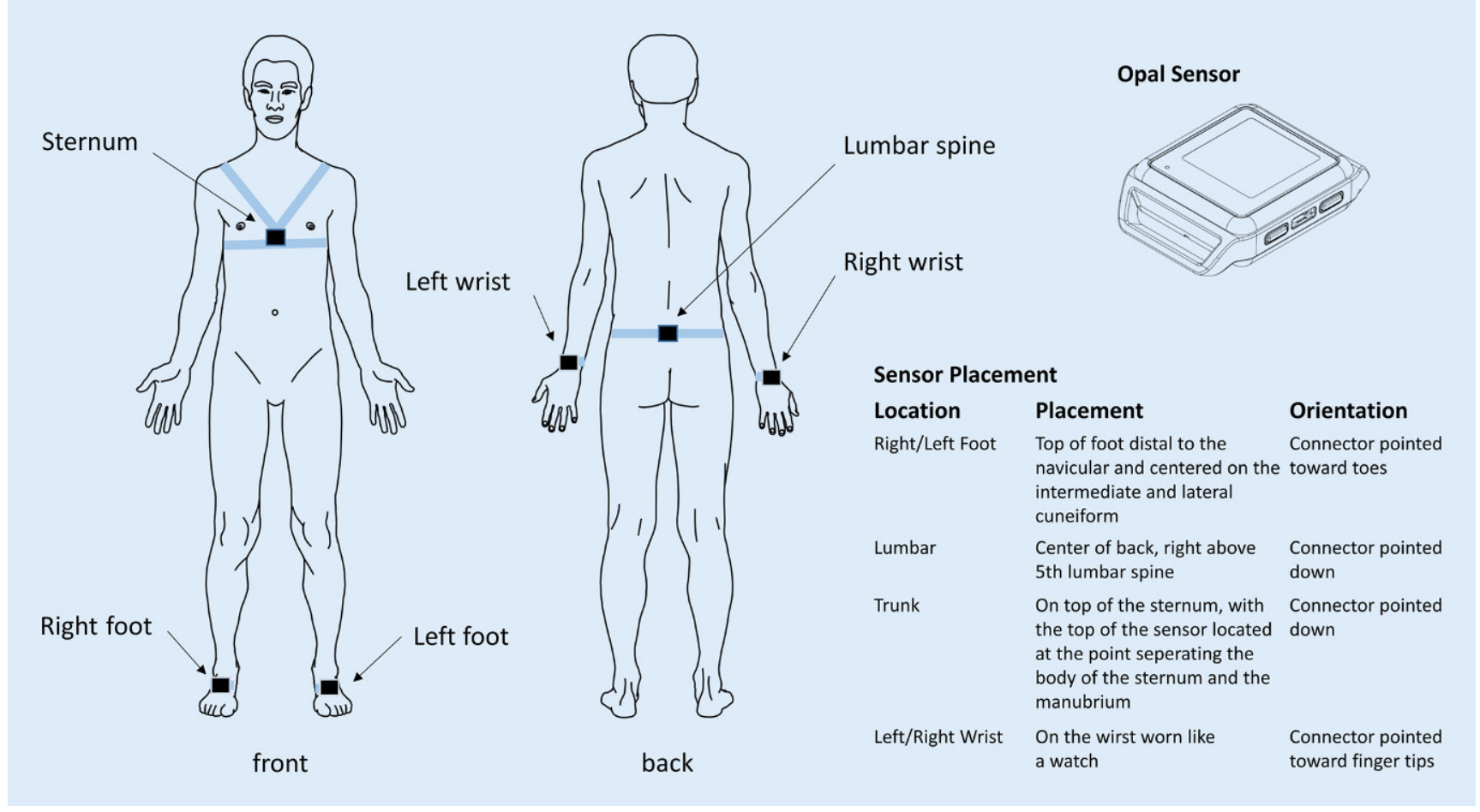

Fig. $1 \Delta$ Sensor placement. A total of 6 sensors are placed on each subject. The image of the opal sensor is taken from the Mobility Lab ${ }^{\text {TM }}$ User Guide. (Accessed on 22 April 2021 at https://share.apdm.com/documentation/MobilityLabUserGuide. pdf)

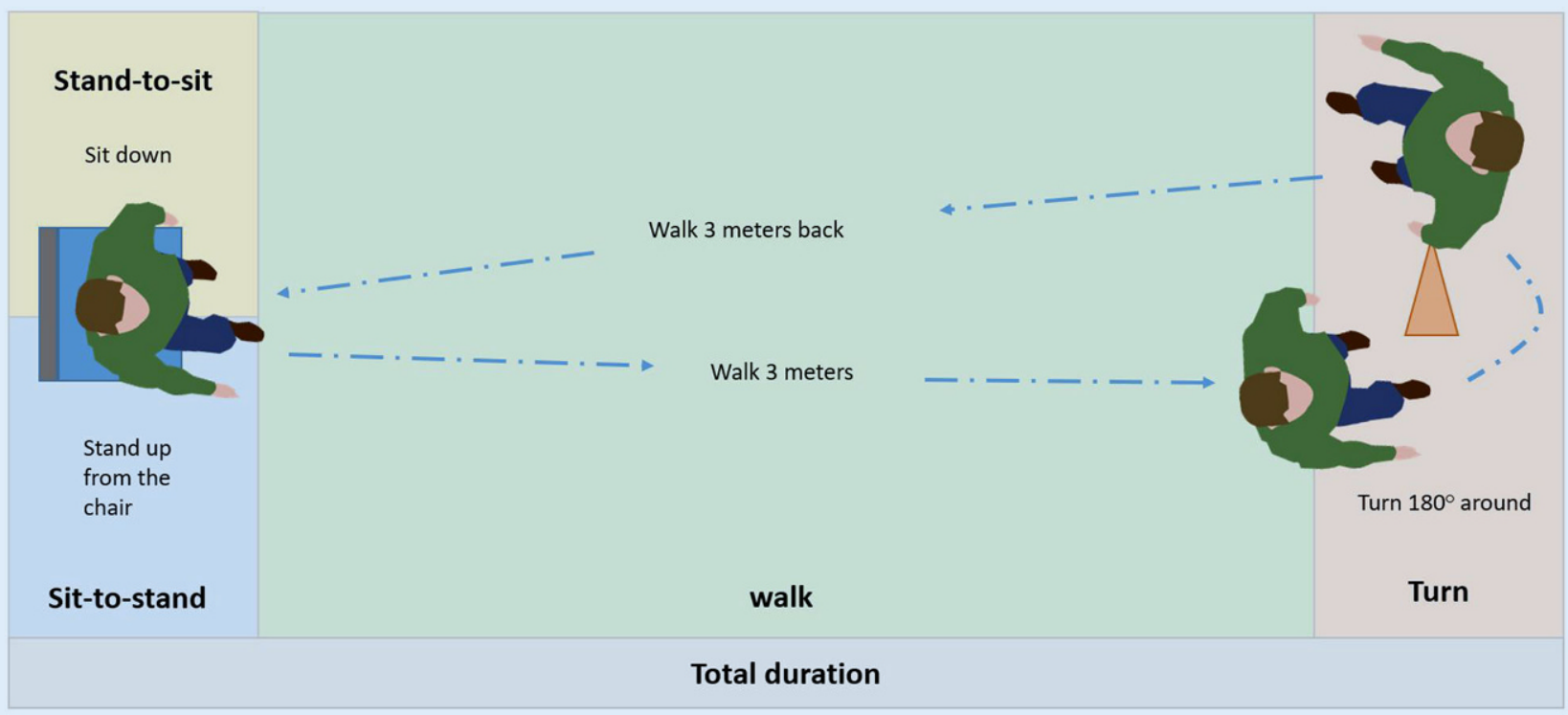

Fig. $2 \Delta$ Illustration of the subphases within the instrumented Timed Up and Go (iTUG) test

required to complete the test was also recorded.

In addition to demographic variables, we recorded body composition (weight and height). The participant's independence in basic ADL was assessed with the Barthel Index (Barthel, 1965) and global cognitive functioning was measured with the Montreal Cognitive Assessment (MoCA, Nasreddine, 2005). The Barthel Index is a scale that measures ten basic aspects of activity related to self-care and mobility (the highest score is 100 , and lower scores indicate greater dependency; Barthel, 1965). Bouwsta and colleagues (2019) demonstrated that the interrater reliability is sufficient to measure and interpret changes in phys- 
ical function in geriatric patients, with an ICC of 0.96 (95\% confidence interval $[0.93,0.98])$. The MoCA includes measures of executive functions, language, memory, attention, orientation, calculation, and visuospatial ability. The score ranges between $0-30$, with scores below 26 indicate mild cognitive impairment with $100 \%$ sensitivity and $87 \%$ specificity (Nasreddine et al., 2005). The MoCA also demonstrated a high test-retest reliability. Using the ICC values ranging from 0.75 to 0.92 , indicate a fairly high to a high reliability over time periods ranging from 4 weeks to 18 months (Ozer, Young, Champ, \& Burke, 2016).

\section{Multicomponent exercise intervention}

The intervention was developed by Wollesen (2018; Bischoff et al., 2021) for the "Prevention and occupational health in long-term care" (PROCARE) project. The study protocol was published in Cordes et al. (2019). The duration of the intervention was 16 weeks with 2 sessions per week ( 32 sessions). Each session lasted between $45-60 \mathrm{~min}$ and was conducted by a certified exercise scientist or physiotherapist with a maximum group size of 10 people. The program combines published exercises that are beneficial for cognitive-motor performance in older adults (community-dwelling as well as institutionalized) (Liu \& Latham, 2009; Fiatarone, 2019; Thomas, Mackintosh, \& Halbert, 2010; Wollesen \& VoelckerRehage, 2014; Wollesen et al., 2017). In addition, the exercise program was continuously adapted to the residents' capacity and, hence, is organized as a progressive challenge to expand participants' resources according to the F.I.T.T. (Frequency, Intensity, Time, and Type of exercise) principle (Garber et al., 2011) and the recommendations of the Global Aging Research Network (IAGGGARN) and the IAGG European Region Clinical Section for physical activity in older persons (de Souto Barreto et al., 2016). Further information on the multicomponent exercise program can be found under Cordes et al. (2019).

\section{Data acquisition and procedure}

The assessment took place upon entry to the study (pretest) and was repeated after 16 weeks (posttest).

Thus, the iTUG was administered twice, one trial at baseline and one trial in the posttest. The participants were required to walk at a self-selected and comfortable walking speed. After preparation (attachment of the sensors), participants sat on a standard chair with their arms at their sides. They were instructed as follows: "When I say 'Go', I want you to get up from the chair, walk straight ahead at your comfortable walking pace, turn around, and then walk back to the chair and sit down". The test was completed when the participant was seated again. The chair was positioned against a wall to ensure that the chair was stable when standing up and sitting down. A researcher with previous experience in this procedure administered the iTUG. Participants were instructed not to use their hands, neither during the sit-to-stand phase nor during the standto-sit phase. No specification was made as to which leg the test person should start off with or in which direction he or she should turn. The main parameter was the duration in the subphases and the total duration of the iTUG test in seconds.

\section{Statistical analysis}

Data was analyzed using SPSS version 25.0 (SPSS Inc., Chicago, IL, USA). First, we examined the duration in each subphase for missing values, normality of distributions (tested by Kolmogorov-Smirnov tests), and the presence of outliers. An alpha ( $\alpha$ ) level of 0.05 was used for all statistical tests. Group comparison for continuous variables (such as age, body mass index [BMI], MoCA) were assessed using analysis of variance (ANOVA); sex as categorical demographic variable was compared using chi-square $\left(\mathrm{X}^{2}\right)$. To analyze the effect of the intervention on each subphase of the iTUG, a 3 (groups) $\times 2$ (time) analysis of covariance (ANCOVA) with repeated measures was calculated for the duration in each subphase with pretest control as a covariate and a priori contrasts. Due to baseline adjustment, any interaction effect would produce the same results as the main effect group. Therefore, the main effects for group were not reported. Effect sizes for all ANOVAs were reported using partial eta squared $\left(\eta_{\mathrm{p}}^{2}\right)$ (Lakens, 2013), with a small effect defined as 0.01 , a medium effect as 0.06 , and a large effect as 0.14 (Cohen, 1988). There were different numbers of missing values in the subphases because the iTUG algorithm in the Mobility Lab ${ }^{\text {Tm }}$ software could not reliably detect these parameters (sit-to-stand: 22; walking: 26; turning: 2; stand-to-sit: 10). For the iTUG total duration, the dataset was complete.

In addition, the percentage changes between pre- and posttest were calculated for each participant: (( (pretest - posttest) / pretest $\left.{ }^{*} 100\right)$ and correlated with the attendance rates (•Table 2). Linear mixed-effects modeling was utilized to determine the moderation effect of cognitive performance (MoCA), age, and the independence/need of care (Barthel Index) on the relationship between attendance rate and intervention effect in the iTUG total duration using the PROCESS macro in SPSS (Hayes, 2017). The simple moderation model we used in this study was Model \#1. Thus, three moderation analyses were conducted to determine whether the interaction between the independent variables (MoCA, age, and Barthel Index) and the attendance rate significantly predicted the intervention effect. Significant transition points within the observed range of the moderator were analyzed using an application in the PROCESS macro, called the Johnson-Neyman method (Johnson \& Neyman, 1936). The relationship of all variables involved in the moderation analysis was approximately linear, as visually shown in the scatterplots after LOESS smoothing (Jacoby, 2000).

\section{Results}

\section{Participants}

- Table 1 shows the characteristics of the sample. In the group with low attendance 


\begin{tabular}{|c|c|c|c|c|c|}
\hline Subphase & $\begin{array}{l}\text { iTUG total } \\
\text { duration }\end{array}$ & $\begin{array}{l}\text { iTUG sit-to-stand } \\
\text { duration }\end{array}$ & $\begin{array}{l}\text { iTUG walk } \\
\text { duration }\end{array}$ & $\begin{array}{l}\text { iTUG turn } \\
\text { duration }\end{array}$ & $\begin{array}{l}\text { iTUG stand-to-sit } \\
\text { duration }\end{array}$ \\
\hline $\begin{array}{l}\text { Correla- } \\
\text { tion }(r)\end{array}$ & $0.328^{*}$ & 0.029 & -0.124 & 0.066 & $0.301^{*}$ \\
\hline pvalue & 0.010 & 0.439 & 0.195 & 0.328 & 0.029 \\
\hline$N$ & 50 & 28 & 50 & 48 & 40 \\
\hline
\end{tabular}

${ }^{*}$ Correlation is significant at level 0.01 (one-sided), ${ }^{* *}$ Correlation is significant at level 0.05 (one-sided)

an attendance rate of $3.09 \%( \pm 5.26)$ was recorded, a rate of $50.1 \%( \pm 10.1)$ in the group with moderate attendance, and a rate of $88.3 \%( \pm 10.3)$ in the group with high attendance. Distributions of age, sex, BMI, and MoCA scores did not differ between groups. The MoCA total score was $16.7( \pm 0.86)$ points for all residents, which is below the cutoff value (19 points) for discriminating between mild cognitive impairment and Alzheimer's disease (Roalf et al., 2013). In all, $63.3 \%$ of the participants were thus screened as showing signs of dementia. German reference data for the prevalence of dementia for nursing home residents are $51.8 \%$ (Hoffmann, Kaduszkiewicz, Glaeske, van den Bussche, \& Koller, 2014), which is lower than the prevalence values of the present sample, based on the MoCA results in this study (63.3\% $<19$ points). Most participants were of normal weight in all groups following the BMI guidelines from several expert panels (Villareal et al., 2005; NHLBI Expert Panel, 1998). Participants were classified as moderately dependent with a Barthel Index mean score of $75( \pm 6.03)$ points (Shah, Vanclay, \& Cooper, 1989).

\section{Intervention effects on the iTUG performance and its subphases}

The 3 (group) $\times 2$ (time) repeated measures ANCOVA for the total duration of the iTUG showed a significant main effect time, $F(1,46)=14.8, p<0.001$, $\eta_{\mathrm{p}}^{2}=0.243$, and a significant interaction effect time $\times$ group $F(2,46)=3.50$, $p=0.038, \quad \eta_{\mathrm{p}}^{2}=0.132$. Regarding the covariate (pretest), there was a significant effect, $F(1,46)=197, p<0.001$, $\eta^{2}=0.811$, and a significant interaction effect covariate $\times$ time, $F(1,46)=11.5$, $p<0.001, \quad \eta^{2}=0.200$. The a priori contrasts showed no significant difference $(p=0.063)$ between the high attendance group $(M=25.4, S E=1.18)$ compared to the moderate attendance group $(M=25.2, S E=1.31)$, but did show a significant difference $(p=0.032)$ compared to the low attendance group $(M=22.4, S E=0.67)$. In the sit-to-stand subphase there was a significant main effect time, $F(1,24)=10.1, p<0.004$, $\eta \eta_{\mathrm{p}}^{2}=0.296$. The interaction effect time $\times$ group was not significant, $F(2$, 24) $=0.018, p=0.758, \eta_{\mathrm{p}}^{2}=0.023$. The effect of the covariate was significant, $F(1$, $24)=10.1, p<0.01, \eta_{p}^{2}=0.296$. A priori contrasts showed no significant differences between groups ( $p=0.554-0.615$ ). Regarding the walking subphase, there was no significant main effect time, $F(1$, $20)=1.46, p=0.242, \eta^{2}=0.068$, nor an interaction time $\times$ group, $F(2,20)=1.26$, $p=0.306, \eta_{\mathrm{p}}^{2}=0.112$. However, the effect of the covariate was significant, $F(1,20)=0.123, p<0.001, \eta^{2}=0.861$. A priori contrast showed no significant difference $(p=0.411)$ between the high attendance group $(M=13.0, S E=1.29)$ compared to the moderate attendance group $(M=15.5, S E=2.57)$, and no significant difference $(p=0.150)$ compared to the low attendance group $(M=17.4$, $S E=2.57)$. For the turn subphase, a significant main effect time, $F(1,44)=13.9$, $p<0.001, \eta_{\mathrm{p}}^{2}=0.240$, but no interaction effect time $\times$ group, $F(2,44)=0.438$, $p=0.648, \eta_{\mathrm{p}}^{2}=0.020$, has been observed. The effect of the covariate was significant, $F(1,44)=104, p<0.001, \eta_{\mathrm{p}}^{2}=0.704$. A priori contrasts revealed no significant differences $(p=0.376-0.938)$ between groups (- Fig. 3). In the stand-to-sit subphase a significant main effect time, $F(1,36)=12.0, p<0.001, \eta_{\mathrm{p}}^{2}=0.250$, has been reported. The interaction effect time $\times$ group was not significant, $F(2$,
36) $=2.03, p=0.146, \eta_{\mathrm{p}}^{2}=0.102 . \quad$ The effect of the covariate was significant, $F(2,36)=76.2, \quad p<0.001, \quad \eta^{2} \mathrm{p}=0.679$. A priori contrasts showed no significant difference $(p=0.218)$ between the high attendance group $(M=0.90$, $S E=0.36)$ compared to the moderate group $(M=1.01, S E=0.07)$, and a tendence towards a significant difference $(p=0.074)$ compared to the low attendance group $(M=1.04, S E=2.57)$.

\section{Relationship between attendance rate and percentage change between pretest and posttest of the iTUG}

We observed a significant correlation between the attendance rate and the iTUG total duration $(r(50)=0.328, p=0.010)$. The higher the attendance rate, the greater the percentage change from pre- to posttest. A significant relationship with the attendance rate was observed for the iTUG stand-to-sit duration $(r(40)=0.301, p=0.029)$. Thus, an increased percentage reduction in duration was found with an increased rate of attendance. The correlations with the other subphases were not significant $(r=-0.124-0.66, p=0.195-0.440$; - Table 2 and 0 Fig. 6).

Regarding the iTUG total duration, there was a moderating effect of functional independence (Barthel Index) on the relationship between attendance rate and the intervention effect (• Fig. 4). The overall model showed that $21.9 \%$ of the intervention effects can be significantly $(p=0.012)$ explained by the model. Functional independence (Barthel Index) significantly moderated the effect between attendance rate and the iTUG total duration, $\Delta R^{2}=8.34 \%, F(1$, $44)=4.69, p=0.036,95 \%$ CI $[0.001$, 0.027]. The moderator value defining the Johnson-Neyman significance was 70.07 ( $41.7 \%$ of the participants were below this value and $58.3 \%$ of participants were above this value; - Fig. 5). $\operatorname{MoCA}\left(\Delta R^{2}=0.05 \%, \quad F(1,45)=0.25\right.$, $p=0.875,95 \% \mathrm{CI}[-0.038,0.044])$ and age $\left(\Delta R^{2}=4.35 \%, F(1,46)=2.53, p=0.118\right.$, $95 \%$ CI $[-0.068,0.058])$ did not have a moderating effect. 
low attendance rate $(<1 / 3)$

moderate attendance rate $(1 / 3-2 / 3)$

wigh attendance rate ( $\geq 2 / 3)$

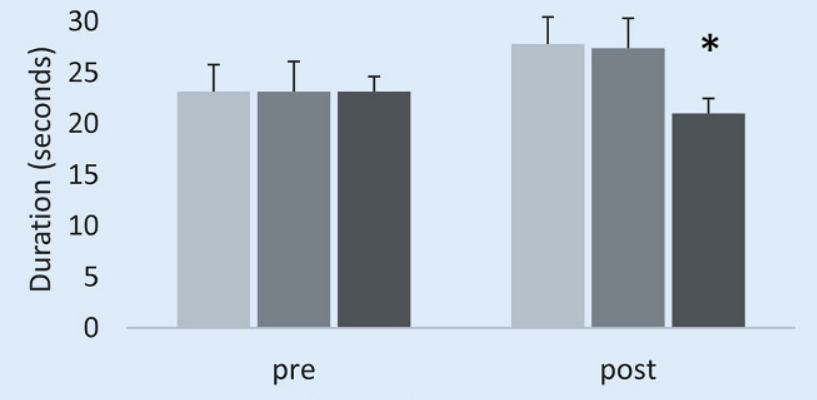

a

Time of measurement

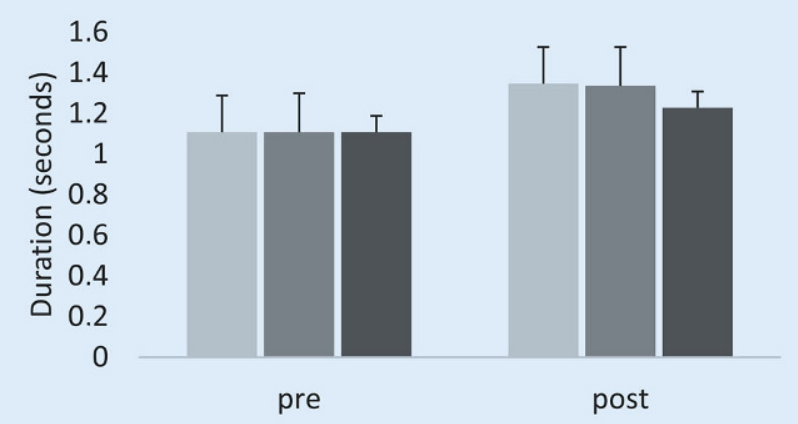

b

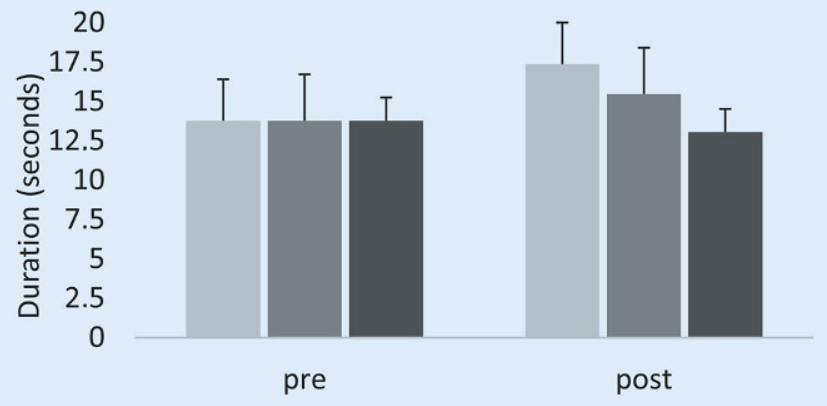

C

Time of measurement

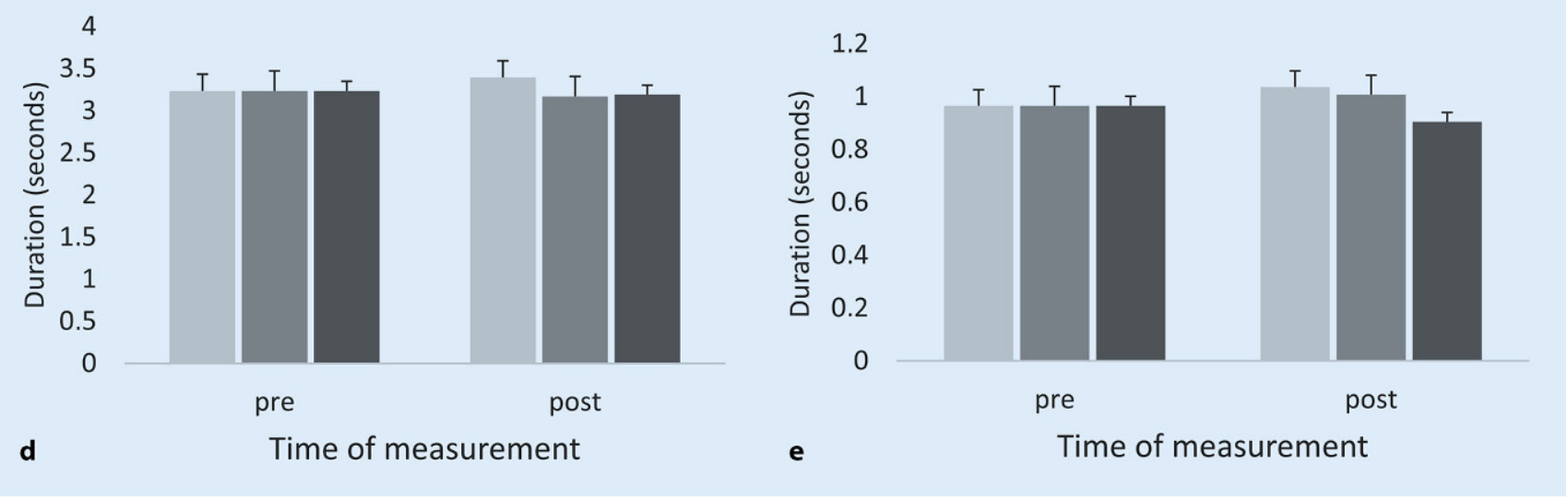

Fig. $3 \Delta$ Means and standard errors for the duration of the instrumented Timed Up and Go (iTUG) test subphases in pre- and posttest. a Total duration, $\mathbf{b}$ sit-to-stand duration, $\mathbf{c}$ walk duration, $\mathbf{d}$ turn duration, e stand-to-sit-duration. Covariates in the model are evaluated for the following values: iTUG total duration $=23.1$; iTUG walk duration $=13.8$; iTUG sit-to-stand duration $=1.11$; iTUG stand-to-sit duration $=0.965$; iTUG turn duration $=3.24$. Asterisk significant interaction effect time $\times$ group was only observed for total duration. A prior contrasts showed significant differences between the low attendance group compared to the high attendance and moderate attendance groups

- Figure 6 shows that $30 \%$ of nursing home residents $(n=3)$ in the group with a low attendance rate, $25 \%(n=2)$ in the group with a moderate attendance rate, and $62.5 \%(n=20)$ in the group with a high attendance rate improved in total iTUG performance (\% change in iTUG total duration $>0 \%)$. Following Masciocchi, Maltais, Rolland, Vellas, and de Souto Barreto (2019) and assuming an 11.2\% decrease in TUG total performance over 4 months, $40 \%(n=4)$ in the low attendance group, $62.5 \%(n=5)$ in the moderate attendance group, and $78.1 \%(n=25)$ in the high attendance group showed a positive effect of the multicompoment exercise intervention.

\section{Discussion}

This study aimed to evaluate the iTUG as a tool to measure the effects of a multicomponent exercise intervention on the iTUG subphases in nursing home residents, particularly concerning the subphases, and to evaluate the impact of the attendance rate on iTUG changes. 

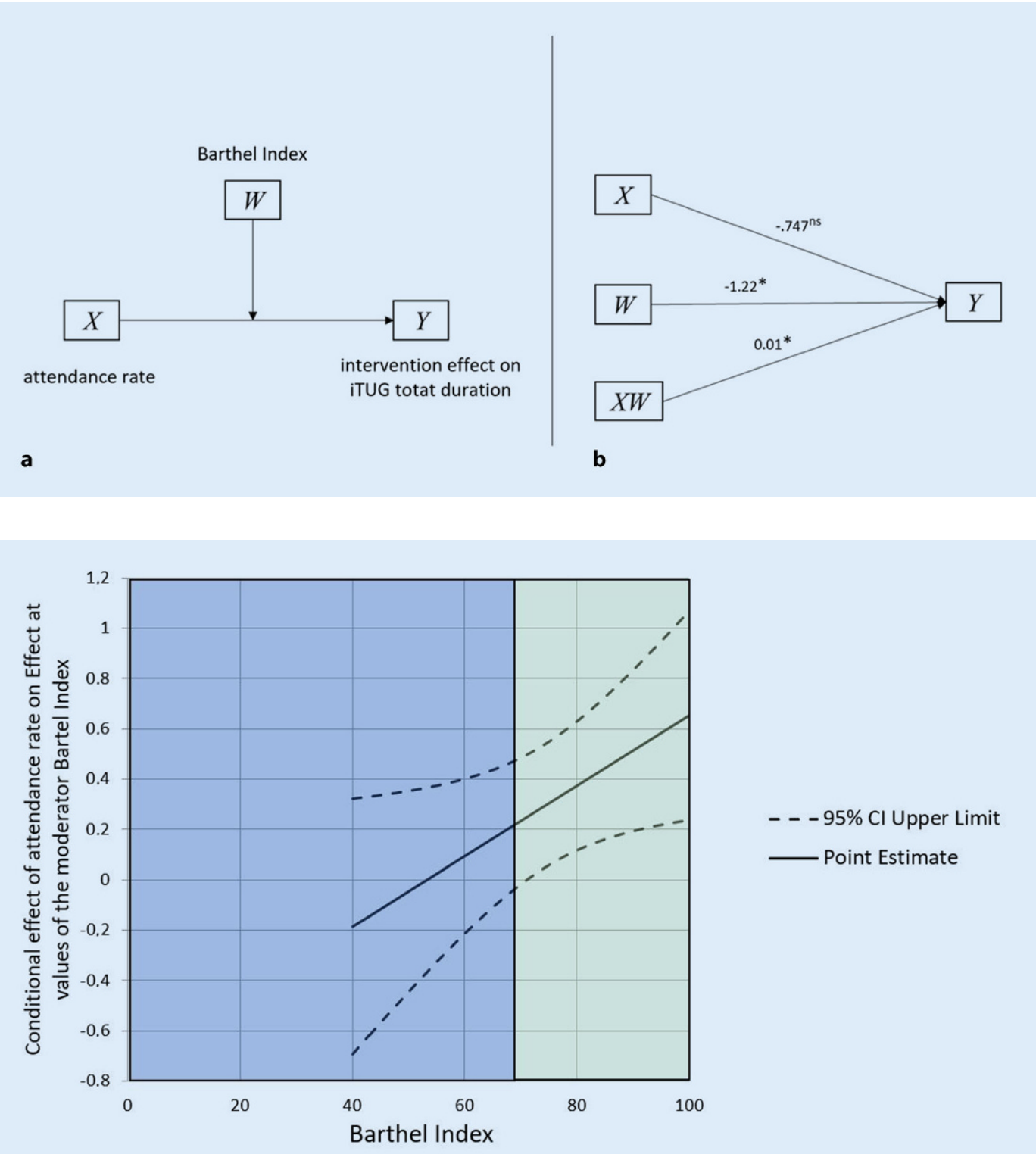

Fig. $4<$ a Representation and conceptual form of the moderation model. b Statistical form and path coefficients for the moderated model. Asterisks indicate statistical significance and $\left({ }^{n s}\right)$ indicates no significance
Fig. $5<$ Visualizing the conditional moderator effect of the functional independence (Barthel Index). The moderating effect becomes significant above a Barthel Index of 70.07 (green colored area)
One may assume that the nursing home residents participating in our study would be among the fitter individuals, since participation required specific physical abilities. This should be considered when assessing the representativity of the sample. Indeed, the range of TUG performance in nursing home residents was extensive ( $<10$ up to $>150$ s). Some studies reported longer durations in a similar sample (Baum et al., 2003; Johnen \& Schott, 2018; Henskens, Nauta, Van Eekeren, \& Scherder, 2018), although some examined nursing home residents with dementia. Other studies reported shorter TUG total durations at baseline (Arrieta et al., 2018; Benavent-
Caballer, Rosado-Calatayud, SeguraOrtí, Amer-Cuenca, \& Lisón, 2014; Cadore et al., 2014; Meng et al., 2017; Kocic et al., 2018); however, some of them studied cognitively unimpaired individuals or older adults in the assisted living environment. Other findings in this setting and age group are similar to our results at baseline (Cancela, Ayán, Varela, \& Seijo, 2016; Mouton et al., 2017; Zarzeczny et al., 2017; Holmerová et al., 2010). A significant interaction of pretest performance $\times$ time with a concurrent interaction effect time $\times$ group for iTUG total duration suggests that residents with high iTUG performance at baseline benefit more from the interven- tion than residents who started at lower iTUG performance levels. Our results contradict the findings by Fairhall et al. (2012), in which they found a higher effect of the intervention on gait speed among frail older people. It is not surprising, as mobile residents were less dependent on caregivers and were able to come to interventions independently. This could have led to lower attendance rates for less mobile residents, as it was not always possible to ensure that they were ready on time or that the caregivers always reliably brought them to the intervention. The moderating effect of a person's functional independence (which is above a Barthel Index of 70.07) 


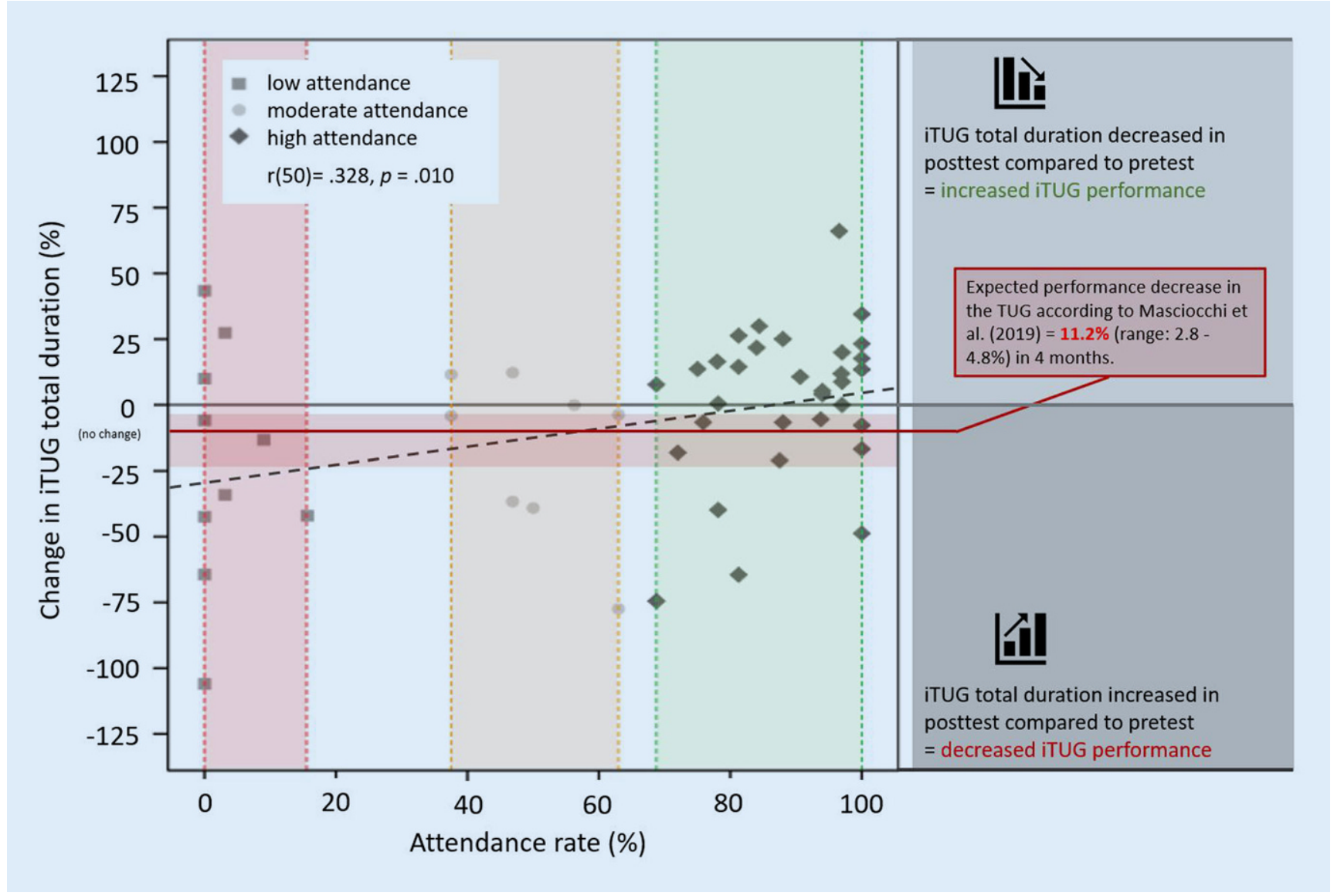

Fig. $6 \Delta$ Percentage changes in the instrumented Timed Up and Go (iTUG) total duration for each group and as a function of the attendance rate

on the relationship between attendance rate and intervention effect in the iTUG total duration also confirmed that. The moderation was able to explain an additional $8.34 \%$ of the variance, which can be interpreted as moderate according to Cohen (1988).

The significant interaction effect time $\times$ group for the iTUG total duration indicated that a high attendance rate positively affected the iTUG performance and its subphases. With increasing attendance, we saw larger effects for the total duration and the stand-to-sit subphase, indicating a dose-response effect of the intervention. This is consistent with Fairhall et al. (2012), who showed that higher adherence was significantly associated with better performance for most outcomes. Nevertheless, the absence or slowing down of the decline in physical performance can, in principle, be interpreted as a sign of the effectiveness of the intervention since the natural decline in physical function is considered normal in nursing home residents. Masciocchi et al. (2019) reported in their narrative review that performance in the TUG test declined by an average of $2.8 \%$ (range $0.7-6.2 \%$ ) per month when nursing home residents did not attend any additional physical exercise therapy. This natural decline can be explained by the high sedentary times among nursing home residents (Harvey, Chastin, \& Skelton, 2015; Healy et al., 2011; McArthur, 2019; Jansen, Diegelmann, Schnabel, Wahl, \& Hauer, 2017). Applied to our intervention duration of 4 months, this would predict a decline of $11.2 \%$ if a linear decline is assumed. In our study, we observed even higher declines of $22.7 \%$ in the group with a low attendance rate; however, in the group with a high attendance rate, we saw a positive effect of the intervention in $78.1 \%(n=25)$ of the residents.
Regarding the subphases, we observed that residents in the group with a high attendance rate improved or maintained their TUG performance in all subphases compared to the other groups. However, these group differences were not significant. A possible explanation could be the relatively small number of participants and values that were not provided by the system because the Mobility $\mathrm{Lab}^{\mathrm{Tm}}$ algorithm could not detect them. The sit-to-stand subphase, for example, was the least reliable component (with 22 missing values), probably due to the large degrees of freedom available to nursing home residents, who can use a variety of strategies to perform this activity (Janssen, Bussmann, \& Stam, 2002). As seen, the acceleration patterns in these subphases of the iTUG can be very heterogeneous, which makes detection based on the acceleration peaks more difficult. In addition, the training program focused on improving walking per- 
formance, coordination, balance, dualtask performance, mobility and cognitive performance. Strength exercises, e.g., for the lower extremities, which appeared to be important for the sit-to-stand subphase, were addressed only secondarily. In previous studies, lower extremity training has been shown to affect standing up and mobilization in general. For example, Johnen \& Schott (2018) showed that nursing home residents significantly improved their physical performance in the TUG and 30-second Chair Stand test after resistance training for the upper and lower extremities with both free weights and machines. In this study however, the subphases were not considered. Regarding the sit-to-stand subphase, a meta-analysis on intervention effects in stroke patients indicated a significant overall effect estimate in favor of the intervention group (standardized mean difference [SMD] -0.34; 95\% CI [-0.62,-0.06], seven studies; Pollock, Gray, Culham, Durward, \& Langhorne, 2014), and a recently published study by Kasch (2021) showed that 12 weeks of progressive strength training decreased the duration in the sit-to-stand subphase up to $22 \%$ in patients with multiple sclerosis. The improvements in the sit-tostand subphase in our study could be explained by the strength training and range of motion exercises for the hip and trunk within the intervention program (Cordes et al., 2019). This apparently led to increased strength in the lower extremities and a better lean angle in the sit-to-stand phase, and thus to a shorter duration in the iTUG.

There are nevertheless some limitations that need to be addressed. In addition to cognitive performance, which may influence performance in the iTUG and the intervention effect, there are other factors that we did not examine in this study. These include depression, fear of falling, and other emotional factors that play a crucial role and affect one another (Kose, Cuvalci, Ekici, Otman, \& Karakaya, 2005). Unlike the PROCARE study (Cordes et al., 2019), we did not conduct a retention test to examine the persistent effects on iTUG performance. A retention test is mandatory but quite difficult in the nursing home setting given the high mortality rate in this age range, making it hard to provide suggestions on the sustained effects of a specific intervention.

Moreover, it would have been useful to compare the intervention group with a control group that did not receive this intervention. Since we did not have a traditional control group, we divided the groups according to their attendance rate. This did allow for a better illustration of the intervention effects as a function of visit frequency. We decided to divide participants who visited two-thirds of the units (Hawley-Hague et al., 2016) and compared this group with those with lower attendance rates. Studies reporting mean attendance rates should provide more details, such as the range of attended sessions, at least in studies with small samples, (e.g., Henskens et al., 2018, p. 69: "Mean attendance to the intended 72 exercise sessions was $55 \%$ $[$ mean $=39.5, \mathrm{SD}=20.8$; range $=0-64]$. .) . Besides, it is important to consider how lower attendance rates occurred. This may have different outcome effects for someone who had to stop attending the intervention sessions for several weeks (maybe, due to some personal reasons) to someone who regularly attended the intervention sessions. We examined irregularities related to the attendance rate and factored in unpredictable circumstances (such as people suffering from stroke or a disease), but this did not justify excluding this group of participants. Overall, we had a relatively small number of participants, so the subphases between these groups did not become significant. Furthermore, a priori power analysis was not performed. Studies with a higher number of participants and additional measures to assess TUG performance (such as number of steps in the turning phase, turning strategies, lean angle in the sit-to-stand and stand-tosit subphase) could have led to a more differentiated interpretation of the intervention effects. These additional parameters allow to detect obvious impairments or changes and capture subtle differences and thus provide a better description of motor processes. Sensor-based analysis systems and the associated algorithms (Caldas, Mundt, Potthast, de Lima Neto,
\& Markert, 2017), which can sensitively capture different measures (biomarkers), play a crucial role in long-term observations and for documenting intervention successes. The downside is that these systems are cost-intensive and can only be used in the care setting with considerable effort. In this regard, modern smartphones have a growing number of inertial and location sensors, such as accelerometers, GPS, gyroscopes, and magnetometers, and are comparably user-friendly. To what extent sensor-based systems will be used in the nursing home setting to investigate alternative motion parameters remains to be seen. Ponciano, Pires, Ribeiro, and Spinsante (2020) conducted a systematic review of how inertial sensors embedded in mobile devices were used to measure various parameters of the iTUG test in older people. The authors stated that together with mobile devices using open source technologies, iTUG is very accessible to all. Persons without experience with nursing home residents and the application of the TUG should be alert to potential accidents. For safety reasons, the resident should be accompanied during the iTUG. Also, an alternative and secure realization of the iTUG is to use two chairs; one chair with the seat facing the wall and another against the backrest. This prevents the chair from tipping over and avoids subjects injuring their heads on the wall if they lose their balance and fall backwards while sitting down. This alternative was not applied but was considered the safer alternative during the course of data collection. For comparability reasons we did not change the setup. Our findings have potential implications for assessing intervention effects in nursing home residents. We have approved the iTUG test as a potential tool for measuring the effects of a multicomponent exercise intervention on physical function and balance in nursing home residents. We observed changes in the iTUG performance especially in the group with high attendance rates. Therefore, the iTUG performance can be highly recommended as an evaluation tool for intervention effects. In addition to the total TUG duration, other parameters should be considered in the different subphases. The exercises 
in the intervention programs could be adjusted accordingly to induce significant differences in these subphases. For this to work, however, gait analysis systems must measure these subphases reliably and sensitively. Factors emanating from the individual, such as fear of discomfort or pain, anxiety or depression, and limitations due to neuromuscular or musculoskeletal impairment, may influence the iTUG performance and the subphases. For example, external factors include forced rest for therapeutic purposes (Herdman et al., 2021). These factors must also be considered if we want to examine the effects on physical function and balance in nursing home residents. A more detailed view of the intervention effects on mobility will be provided by the results of the multicenter PROCARE project using different evaluation criteria (Cordes et al., 2019).

\section{Conclusion}

Overall, we strongly believe that the iTUG test can be recommended as a vital tool to measure the effects of a multicomponent exercise intervention on physical function and balance in nursing home residents. However, individuals need to attend a sufficient number of sessions to observe a positive effect on the iTUG performance. Our study showed that especially mobile, independent residents frequently participated in the training and thus were able to benefit the most. Due to the low number of participants, we cannot make any definite statements, particularly regarding the subphases of the iTUG. The algorithms included in the different measurement systems do not seem to be developed enough to represent reliable and sensitive parameters for intervention effects, especially for a specific group of people. Future studies should focus on making adaptations to the algorithms, especially for participants who shuffle when walking and hardly lift their feet.

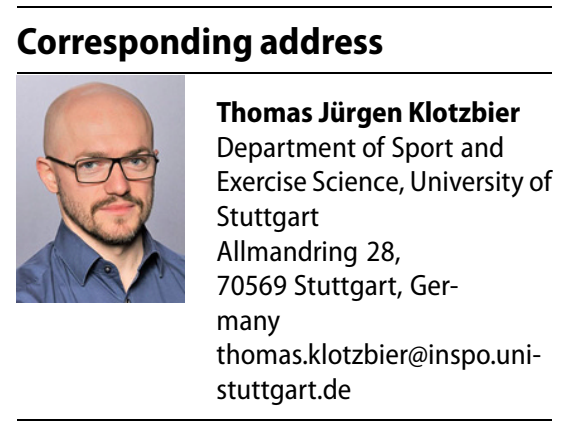

Acknowledgements. The authors thank the volunteers who participated in the study. Many thanks also to Rubina Chandnani for proofreading the manuscript.

Funding. This study was supported by the health insurance Techniker Krankenkasse. The views expressed in this paper are those of the authors and may not be shared by the funding bodies. The study is part of the project "Prevention and occupational health in long-term care" (PROCARE; Head of the consortium: Prof. Dr. Bettina Wollesen, University of Hamburg). Trial data were analyzed independently of the trial sponsors. This funder did not play any role in the design of the study, data collection and analysis, reporting of results, or the decision to present the manuscript for publication.

Author Contribution. We confirm that all authors were fully involved in the study, prepared the manuscript and provided the material within it. All authors fulfill the ICMJE (International Committee of Medical Journal Editors) recommendations on authorship. Credit taxonomy: T. J. Klotzbier: Conceptualization, Methodology, Formal analysis, Investigation, Writing-Original Draft, Writing-Review \& Editing, Visualization, Data Curation; H. Korbus: Conceptualization, Investigation, Methodology, Writing-Original Draft, Review \& Editing; B. Johnen: Conceptualization, Investigation, Methodology, Writing - Original Draft, Review \& Editing; N. Schott: Conceptualization, Methodology, Analysis, Writing一Original Draft, Review \& Editing, Resources.

Funding. Open Access funding enabled and organized by Projekt DEAL.

\section{Declarations}

Conflict of interest. The authors have no financial or personal relationships with any other person or organization that could improperly influence or otherwise influence their work in this study. T. J. Klotzbier, H. Korbus, B. Johnen and N. Schott declare that they have no competing interests.

All procedures performed in studies involving human participants or on human tissue were in accordance with the ethical standards of the institutional and/or national research committee and with the 1975 Helsinki declaration and its later amendments (World Medical Accociation, Fortaleza, 2013) or comparable ethical standards. The study was approved by the Ethics Committee of the Hamburg Chamber of Physicians (registration number PV5762). All nursing home residents or their legal guardians received written and verbal information about the study and signed informed consent prior to their participation. Informed consent was obtained from all individual participants included in the study.

Open Access. This article is licensed under a Creative Commons Attribution 4.0 International License, which permits use, sharing, adaptation, distribution and reproduction in any medium or format, as long as you give appropriate credit to the original author(s) and the source, provide a link to the Creative Commons licence, and indicate if changes were made. The images or other third party material in this article are included in the article's Creative Commons licence, unless indicated otherwise in a credit line to the material. If material is not included in the article's Creative Commons licence and your intended use is not permitted by statutory regulation or exceeds the permitted use, you will need to obtain permission directly from the copyright holder. To view a copy of this licence, visit http://creativecommons.org/licenses/by/4.0/.

\section{References}

Allison, L. K., Painter, J. A., Emory, A., Whitehurst, P., \& Raby, A. (2013). Participation restriction, not fear of falling, predicts actual balance and mobility abilities in rural community-dwelling older adults. Journal of Geriatric Physical Therapy, 36(1), 13-23.

APDM, Inc., Wearable Technologies (2020). Mobility lab user guide. https://share.apdm. com/documentation/MobilityLabUserGuide. pdf. Accessed 22 Apr 2021.

Arrieta, H., Rezola-Pardo, C., Gil, S. M., Irazusta, J., \& Rodriguez-Larrad, A. (2018). Physical training maintains or improves gait ability in long-term nursing home residents: A systematic review of randomized controlled trials. Maturitas, 109, 45-52.

Au-Yeung, S. S., Ho, H. P., Lai, J. W., Lau, R. W., Wong, A. Y., \& Lau, S.K. (2002). Did mobility and balance of residents living in private old age homesimprove after a mobility exercise program? A pilot study. Hong Kong Physiotherapy Journal, 20(1), 16-21.

Barker, A. L., Nitz, J. C., Choy, N. L. L., \&Haines, T. P. (2012). Mobility has a non-linear association with falls risk among people in residential aged care: an observational study. Journal of Physiotherapy, 58(2), 117-125.

Barthel, D.W. (1965). Functional evaluation: the Barthel index. Maryland State Medical Journal, 14,61-65.

Baum, E.E., Jarjoura, D., Polen, A.E., Faur, D., \& Rutecki, G. (2003). Effectiveness of a group exercise program in a long-term care facility: a randomized pilot trial. Journal of the American Medical Directors Association, 4(2), 74-80.

Benavent-Caballer, V., Rosado-Calatayud, P., SeguraOrtí, E., Amer-Cuenca, J. J., \& Lisón, J. F. (2014). Effects of three different low-intensity exercise interventions on physical performance, muscle CSA and activities of daily living: a randomized controlled trial. Experimental Gerontology, 58, 159-165.

Bischoff, L. L., Cordes, T., Meixner, C., Schoene, D., Voelcker-Rehage, C., \& Wollesen, B. (2021). Can cognitive-motor training improve physical functioning and psychosocial wellbeing in nursing home residents? A randomized controlled feasibility study as part of the PROCARE project. Aging Clinical and Experimental Research, 33(4), 
943-956. https://doi.org/10.1007/s40520-02001615-y.

Bouwstra, H., Smit, E. B., Wattel, E. M., van der Wouden J. C., Hertogh, C. M., Terluin, B., \& Terwee, C. B. (2019). Measurement properties of the Barthel index in geriatric rehabilitation. Journal of the American Medical Directors Association, 20(4), 420-425.

Bunn, F., Dickinson, A., Barnett-Page, E., Mcinnes, E., \& Horton, K. (2008). A systematic review of older people's perceptions of facilitators and barriers to participation in falls-prevention interventions. Ageing \& Society, 28, 449-472.

Cadore, E. L., Casas-Herrero, A., Zambom-Ferraresi, F., Idoate, F., Millor, N., Gómez, M., Rodriguez-Maña, L., \& Izquierdo, M. (2014). Multicomponent exercises including muscle power training enhance muscle mass, power output, and functional outcomes in institutionalized frail nonagenarians. Age, 36(2), 773-785.

Caldas, R., Mundt, M., Potthast, W., de Lima Neto, F. B., \& Markert, B. (2017). A systematic review of gait analysis methods based on inertial sensors and adaptive algorithms. Gait \& Posture, 57, 204-210.

Cancela, J.M., Ayán, C., Varela, S., \& Seijo, M. (2016). Effects of a long-term aerobic exercise intervention on institutionalized patients with dementia. Journal of Science and Medicine in Sport, 19(4), 293-298.

Cimolin, V., Cau, N., Albedi, G. M., Aspesi, V., Merenda, V., Galli, M., \& Capodaglio, P. (2019). Do wearable sensors add meaningful information to the Timed Up and Go test? A study on obese women. Journal of Electromyography and Kinesiology, 44, 78-85.

Cohen, J. (1988). Statistical power analysis for the behavioural sciences (2nd edn.). : Erlbaum.

Cordes, T., Bischoff, L.L., Schoene, D., Schott, N., Voelcker-Rehage, C., Meixner, C., Appeles, L.M., Bebenek, M., Berwinkel, A., Hildebrand, C., Jöllenbeck, T., Johnen, B., Kemmler, W., Klotzbier T., Korbus, H., Rudisch, J., Vogt, L., Weigelt, M., Wittelsberger, R., Zwingmann, K., \& Wollesen, B. (2019). A multicomponent exercise intervention to improve physical functioning, cognition and psychosocial well-being in elderly nursing home residents: a study protocol of a randomized controlled trial in the PROCARE (prevention and occupational health in long-term care) project. BMC Geriatrics, 19(1), 369.

Costello, E., Kafchinski, M., Vrazel, J., \& Sullivan, P. (2011). Motivators, barriers, and beliefs regarding physical activity in an older adult population. Journal of Geriatric Physical Therapy, 34(3), 138-147.

Davis, J.C., Bryan, S., Best, J.R., Li, L.C., Hsu, C.L., Gomez, C., Vertes, K. A., \& Liu-Ambrose, T. (2015) Mobility predicts change in older adults' healthrelated quality of life: evidence from a Vancouver falls prevention prospective cohort study. Health and Quality of Life Outcomes, 13(1), 1-10.

Dechamps, A., Diolez, P., Thiaudière, E., Tulon, A., Onifade, C., Vuong, T., Helmer, C., \& Bourdel-Marchasson, I. (2010). Effects of exercise programs to prevent decline in healthrelated quality of life in highly deconditioned institutionalized elderly persons: a randomized controlled trial. Archives of Internal Medicine, 170(2), 162-169.

Fairhall, N., Sherrington, C., Kurrle, S.E., Lord, S. R., Lockwood, K., \& Cameron, I. D. (2012). Effect of a multifactorial interdisciplinary intervention on mobility-related disability in frail older people: randomised controlled trial. BMC Medicine, 10(1), 1-13.

Galhardas, L., Raimundo, A., \& Marmeleira, J. (2020). Test-retest reliability of upper-limb proprioception and balance tests in older nursing home residents. Archives of Gerontology and Geriatrics, 104079. https://doi.org/10.1016/ j.archger.2020.104079.

Garber, C. E., Blissmer, B., Deschenes, M. R., Franklin, B. A., Lamonte, M.J., Lee, I. M., Nieman, D.C., \& Swain, D.P. (2011). Quantity and quality of exercise for developing and maintaining cardiorespiratory, musculoskeletal, and neuromotor fitness in apparently healthy adults: guidance for prescribing exercise. Medicine \& Science in Sports \& Exercise, 43(7), 1334-1359.

Giannouli, E., Bock, O., Mellone, S., \& Zijlstra, W. (2016) Mobility in old age: capacity is not performance. BioMed Research International, 3261567.https:// doi.org/10.1155/2016/3261567.

Harvey, J. A., Chastin, S. F., \& Skelton, D. A. (2015). How sedentary are older people? A systematic review of the amount of sedentary behavior. Journal of Aging and Physical Activity, 23(3), 471-487.

Hawley-Hague, H., Horne, M., Skelton, D. A., \& Todd, C. (2016). Review of how we should define (and measure) adherence in studies examining olde adults' participation in exercise classes. BMJ Open, 6(6), e011560. https://doi.org/10.1136/ bmjopen-2016-011560.

Hayes, A.F. (2017). Introduction to mediation, moderation, and conditional process analysis: $a$ regression-based approach.: Guilford.

Healy, G. N., Clark, B.K., Winkler, E.A., Gardiner, P.A., Brown, W. J., \& Matthews, C.E. (2011) Measurement of adults' sedentary time in population-based studies. American Journal of Preventive Medicine, 41(2), 216-227.

Henskens, M., Nauta, I. M., Van Eekeren, M.C., \& Scherder, E. J. (2018). Effects of physical activity in nursing home residents with dementia: a randomized controlled trial. Dementia and Geriatric Cognitive Disorders, 46(1-2), 60-80.

Herman, T., Giladi, N., \& Hausdorff, J. M. (2011). Properties of the 'timed up and go'test: more than meets the eye. Gerontology, 57(3), 203-210.

Hoffmann, F., Kaduszkiewicz, H., Glaeske, G., van den Bussche, H., \& Koller, D. (2014). Prevalence of dementia in nursing home and communitydwelling older adults in Germany. Aging Clinical and Experimental Research, 26(5), 555-559.

Holmerová, I., MacHácová, K., Vanková, H., Veleta, P., Jurasková, B., Hrnciariková, D., Volicer, L., \&Andel, R. (2010). Effect of the exercise dance for seniors (EXDASE) program on lower-body functioning among institutionalized older adults. Journal of Aging and Health, 22(1), 106-119.

Hortobágyi, T., Lesinski, M., Gäbler, M., VanSwearingen, J. M., Malatesta, D., \& Granacher, U. (2015). Effects of three types of exercise interventions on healthy old adults' gait speed: a systematic review and meta-analysis. Sports Medicine, 45(12), 1627-1643.

Jacoby, W. G. (2000). Loess: a nonparametric, graphical tool for depicting relationships between variables. Electoral Studies, 19(4), 577-613.

Jansen, C. P., Diegelmann, M., Schnabel, E. L., Wahl, H.W., \& Hauer, K. (2017). Life-space and movement behavior in nursing home residents: results of a new sensor-based assessment and associated factors. BMC Geriatrics, 17(1), 1-9.

Janssen, W. G., Bussmann, H. B., \& Stam, H. J. (2002). Determinants of the sit-to-stand movement: a review. Physical Therapy, 82(9), 866-879.
Johnen, B., \& Schott, N. (2018). Feasibility of a machine vs free weight strength training program and its effects on physical performance in nursing home residents: a pilot study. Aging Clinical and Experimental Research, 30(7), 819-828. https:// doi.org/10.1007/s40520-017-0830-8

Johnson, P.O., \& Neyman, J. (1936). Tests of certain linear hypotheses and their application to some educational problems. Statistical Research Memoirs, 1, 57-93.

Kasch, S. (2021). Improvements in timing variables for the timed up and go and its subphases following A progressive resistance training program. electronic theses and dissertations. 5239. https:// openprairie.sdstate.edu/etd/5239. Accessed 08 Oct 2021.

King, A.C., Kiernan, M., Oman, R. F., Kraemer, H.C., Hull, M., \& Ahn, D. (1997). Can we identify who will adhere to long-term physical activity? Signal detection methodology as a potential aid to clinical decision making. Health Psychology, 16(4), 380.

Kocic, M., Stojanovic, Z., Nikolic, D., Lazovic, M., Grbic, R., Dimitrijevic, L., \& Milenkovic, M. (2018). The effectiveness of group Otago exercise program on physical function in nursing home residents older than 65 years: a randomized controlled trial. Archives of Gerontology and Geriatrics, 75, 112-118.

Kose, N., Cuvalci, S., Ekici, G., Otman, A. S., \& Karakaya, M.G. (2005). The risk factors of fall and their correlation with balance, depression, cognitive impairment and mobility skills in elderly nursing home residents. Saudi Medical Journal, 26, 978-981.

Kovacs, E., Sztruhar Jonasne, I., Karoczi, C.K. Korpos, A., \& Gondos, T. (2013). Effects of a multimodal exercise program on balance, functional mobility and fall risk in older adults with cognitive impairment: a randomized controlled single-blind study. European Journal of Physical and Rehabilitation Medicine, 49(5), 639-648.

de Labra, C., Guimaraes-Pinheiro, C., Maseda, A., Lorenzo, T., \& Millán-Calenti, J.C. (2015). Effects of physical exercise interventions in frail older adults: a systematic review of randomized controlled trials. BMC Geriatrics, 15(1), 154.

Lakens, D. (2013). Calculating and reporting effect sizes to facilitate cumulative science: a practical primer for t-tests and ANOVAs. Frontiers in Psychology, 4, 863 .

Lazowski, D.A., Ecclestone, N.A., Myers, A.M., Paterson, D. H., Tudor-Locke, C., Fitzgerald, C., Jones, G., Shima, N., \& Cunningham, D. A. (1999). A randomized outcome evaluation of group exercise programs in long-term care institutions. Journals of Gerontology Series A: Biomedical Sciences and Medical Sciences, 54(12) M621-M628.

Liu, C. J., \& Latham, N. K. (2009). Progressive resistance strength training for improving physical function in older adults. Cochrane Database of Systematic Reviews. https://doi.org/10.1002/14651858. CD002759.pub2.

Masciocchi, E., Maltais, M., Rolland, Y., Vellas, B., \& de Souto Barreto, P. (2019). Time effects on physical performance in older adults in nursing home: a narrative review. The Journal of Nutrition, Health \& Aging, 23(6), 586-594.

McArthur, C. (2019). Enhancing opportunities for physical activity among long-term care residents: a narrative review. Journal of Science Communication, 26(2), 90-96. 
McGough, E.L., Logsdon, R.G., Kelly, V.E., \& Teri, L. (2013). Functional mobility limitations and falls in assisted living residents with dementia: physical performance assessment and quantitative gait analysis. Journal of Geriatric Physical Therapy, 36(2), 78-86.

Meng, G., Wang, H., Pei, Y., Li, Y., Wu, H., Song, Y., Guo, Q. Guo, H., Fukushima, S., Tatefuji, T., Wang, J., Du, H., Su, Q., Zhang, W., Shen, S., Wang, X., Dong, R., Han, P., Okazaki, T., Nagatomi, R., \& Niu, K. (2017). Effects of protease-treated royal jelly on muscle strength in elderly nursing home residents: $A$ randomized, double-blind, placebo-controlled, dose-response study. Scientific Reports, 7(1), $1-9$.

Metz, D. H. (2000). Mobility of older people and their quality of life. Transport Policy, 7(2), 149-152.

Mirelman, A., Weiss, A., Buchman, A.S., Bennett, D. A., Giladi, N., \& Hausdorff, J.M. (2014). Association between performance on Timed Up and Go subtasks and mild cognitive impairment: further insights into the links between cognitive and motor function. Journal of the American Geriatrics Society, 62(4), 673-678.

Mouton, A., Gillet, N., Mouton, F., Van Kann, D., Bruyère, O., Cloes, M., \& Buckinx, F. (2017). Effects of a giant exercising board game intervention on ambulatory physical activity among nursing home residents: a preliminary study. Clinical Interventions in Aging, 12,847.

Nasreddine, Z. S., Phillips, N. A., Bédirian, V., Charbonneau, S., Whitehead, V., Collin, I., \& Chertkow, H. (2005). The montreal cognitive assessment, MoCA: a brief screening tool for mild cognitive impairment. Journal of the American Geriatrics Society, 53(4), 695-699.

Netz, Y., Axelrad, S., \& Argov, E. (2007). Group physical activity for demented older adults - feasibility and effectiveness. Clinical Rehabilitation, 21(11) 977-986.

Ozer, S., Young, J., Champ, C., \& Burke, M. (2016). A systematic review of the diagnostic test accuracy of brief cognitive tests to detect amnestic mild cognitive impairment. International journal of geriatric psychiatry, 31(11), 1139-1150.

Podsiadlo, D., \& Richardson, S. (1991). The timed “Up \& Go": a test of basic functional mobility for frail elderly persons. Journal of the American Geriatrics Society, 39(2), 142-148.

Pollock, A., Gray, C., Culham, E., Durward, B.R., \& Langhorne, P. (2014). Interventions for improving sit-to-stand ability following stroke. Cochrane Database of Systematic Reviews, 5. https://doi.org/10.1002/14651858.CD007232. pub4.

Ponciano, V., Pires, I. M., Ribeiro, F. R., \& Spinsante, S. (2020). Sensors are capable to help in the measurement of the results of the Timed-Up and Go Test? A Systematic Review. Journal of Medical Systems, 44(12), 1-16.

Sakamoto, R., \& Miura, Y. (2016). The effect of exercise intervention on frail elderly in need of care: halfday program in a senior day-care service facility specializing in functional training. Journal of Physical Therapy Science, 28(7), 1957-1963.

Schoene, D., Wu, S.M.S., Mikolaizak, A.S., Menant, J. C., Smith, S. T., Delbaere, K., \& Lord, S. R. (2013). Discriminative ability and predictive validity of the Timed Up and Go test in identifying older people who fall: systematic review and meta-analysis. Journal of the American Geriatrics Society, 61(2), 202-208.

Schott, N. (2017). Mobilität im Alter-Doppelaufgabentraining als Therapieform bei neurologischen
Patienten. Swiss Sports \& Exercise Medicine, 66(4), 33-40.

Serra-Rexach, J. A., Bustamante-Ara, N., Hierro Villarán, M., González, G.P., Sanz Ibanez, M.J., Sanz, B., Santamaria, V.O., Sanz, N.G., Prada, A.B.M., Gallardo, C., Romo, G. R., Ruiz J.R., \& Lucia, A. (2011). Short-term, light-to moderate-intensity exercise training improves leg muscle strength in the oldest old: a randomized controlled trial. Journal of the American Geriatrics Society, 59(4), 594-602.

Shafrin, J., Sullivan, J., Goldman, D. P., \& Gill, T. M. (2017). The association between observed mobility and quality of life in the near elderly. PloS One, 12(8), e182920.

Shah, S., Vanclay, F., \& Cooper, B. (1989). Improving the sensitivity of the Barthel Index for stroke rehabilitation. Journal of Clinical Epidemiology, 42(8), 703-709.

Shumway-Cook, A., Brauer, S., \& Woollacott, M. (2000). Predicting the probability for falls in communitydwelling older adults using the Timed Up \& Go Test. Physical Therapy, 80(9), 896-903.

de Souto Barreto, P., Morley, J.E., Chodzko-Zajko, W., Pitkala, K.H., Weening-Djiksterhuis, E., Rodriguez-Mañas, L., Barbagallo, M., Rosendahl, E., Sinclair, A., Landi, F., Izquierdo, M., Vellas, B., Rolland, Y., \& Network, G. G. A. R. (2016). Recommendations on physical activity and exercise for older adults living in long-term care facilities: a taskforce report. Journal of the American Medical Directors Association, 17(5), 381-392.

Sterke, C. S., Huisman, S. L., van Beeck, E. F., Looman, C. W., \& van der Cammen, T. J. (2010). Is the Tinetti Performance Oriented Mobility Assessment (POMA) a feasible and valid predictor of shortterm fall risk in nursing home residents with dementia? International Psychogeriatrics, 22(2), 254.

Stubbs, B., Schofield, P., \& Patchay, S. (2016). Mobility limitations and fall-related factors contribute to the reduced health-related quality of life in older adults with chronic musculoskeletal pain. Pain Practice, 16(1), 80-89.

Thomas, S., Mackintosh, S., \& Halbert, J. (2010). Does the 'Otago exercise program' reduce mortality and falls in older adults?: a systematic review and meta-analysis. Age and Ageing, 39(6), 681-687.

Tiedemann, A., Sherrington, C., \& Lord, S. R. (2011). Predictors of exercise adherence in older people living in retirement villages. Preventive Medicine, 6(52), 480-481.

Toulotte, C., Fabre, C., Dangremont, B., Lensel, G., \& Thévenon, A. (2003). Effects of physical training on the physical capacity of frail, demented patients with a history of falling: a randomised controlled trial. Age and Ageing, 32(1),67-73.

Trautwein, S., Barisch-Fritz, B., Scharpf, A., Ringhof, S. Stein, T., Krell-Roesch, J., \& Woll, A. (2020). Effects of a 16-week multimodal exercise program on gait performance in individuals with dementia: a multicenter randomized controlled trial. $B M C$ Geriatrics, 20(1), 1-19.

Villareal, D. T., Apovian, C. M., Kushner, R. F., \& Klein, S. (2005). Obesity in older adults: technical review and position statement of the American Society for Nutrition and NAASO, The Obesity Society. The American Journal of Clinical Nutrition, 82(5), 923-934.

Von Bonsdorff, M., Rantanen, T., Laukkanen, P., Suutama, T., \& Heikkinen, E. (2006). Mobility limitations and cognitive deficits as predictors of institutionalization among community- dwelling older people. Gerontology, 52(6), 359-365.

Wollesen, B. (2018). Kognitiv-motorische Interferenzen von Senioren beim Gehen unter Doppelaufgabenbedingungen (kumulierte Habilitation). Hamburg: Universität Hamburg.

Wollesen, B., \& Voelcker-Rehage, C. (2014). Training effects on motor-cognitive dual-task performance in older adults. European Review of Aging and Physical Activity, 11(1), 5-24.

Wollesen, B., Mattes, K., Schulz, S., Bischoff, L.L., Seydell, L., Bell, J. W., \& von Duvillard, S. P. (2017). Effects of dual-task management and resistance training on gait performance in older individuals: a randomized controlled trial. Frontiers in Aging Neuroscience, 9, 415 .

Wollesen, B., Fricke, M., Jansen, C. P., Gordt, K., Schwenk, M., Muehlbauer, T., Morawietz, C., Kruse, A., \& Gramann, K. (2020). A three-armed cognitivemotor exercise intervention to increase spatial orientation and life-space mobility in nursing home residents: study protocol of a randomized controlled trial in the PROfit project. $B M C$ Geriatrics, 20(1), 1-15.

World Medical Association. Declaration of Helsinki-Ethical Principles for Medical Research Involving Human Subjects. 64th WMA General Assembly, Fortaleza, Brazil, October 2013. https://www.wma.net/policies-post/wmadeclaration-of-helsinki-ethical-principles-formedical-research-involving-human-subjects/. Accessed 08 Oct 2021.

Zampieri, C., Salarian, A., Carlson-Kuhta, P., Aminian, K., Nutt, J. G., \&Horak, F. B. (2010). The instrumented timed up and go test: potential outcome measure for disease modifying therapies in Parkinson's disease. Journal of Neurology, Neurosurgery \& Psychiatry, 81(2), 171-176.

Zarzeczny, R., Nawrat-Szołtysik, A., Polak, A., Maliszewski, J., Kiełtyka, A., Matyja, B., Dudek, M. Zborowska, J., \& Wajdman, A. (2017). Aging effect on the instrumented Timed-Up-and-Go test variables in nursing home women aged 80-93 years. Biogerontology, 18(4), 651-663. 